International Journal of Engineering \& Technology, $7(4.5)(2018) 68-70$
International Journal of Engineering \& Technology
WPC
Website: www.sciencepubco.com/index.php/IJET
Research paper

\title{
Stress Analysis of Domestic Composite LPG Cylinder Using Classical Lamination Theory (CLT)
}

\author{
CH V K N S N Moorthy ${ }^{1}$, V Srinivas ${ }^{2}$ \\ ${ }^{1}$ Institute of Aeronautical Engineering, Dundigal, Hyderabad, Telangana State, India \\ ${ }^{2}$ GITAM University, Rushikonda, Vishakhapatnam, Andhra Pradesh, India \\ *Corresponding author E-mail:krishna.turbo@gmail.com
}

\begin{abstract}
Conventional Steel Cylinders used for LPG cylinder for domestic applications are not manufactured in a single joint but are welded. While composite cylinders are manufactured in a single joint, Composite components cannot be welded like the steel cylinder. Composite Cylinders are winded using Filament Winding technique. Compared to Steel Cylinders, Composite Cylinders are costlier. As composite cylinders are safer than steel cylinder, composite Cylinders due to a rubber lining inside, they are 100\% leak proof. If mass production of composite cylinders are done then the cost may get reduced. This paper summarizes the design and analysis of the manufacturing of Liquid petroleum gas (LPG) Cylinder using Glass Fibre Reinforced Plastic (GFRP) material. The stresses along all the directions of the ply sequence are also calculated using Classical Lamination Theory (CLT). The fibre stresses along all the directional angles were found to be under the required stress limits. The Metallic boss Calculation \& angle variation at dome is the key parameter and is carried out and determined the tip radius.
\end{abstract}

Keywords: GFRP; Liquefied Petroleum Gas (LPG); Classical Lamination Theory (CLT); Tip Radius; Angle Variation at Dome;

\section{Introduction}

Liquefied petroleum gas (LPG) is a mixture of butane and propane gases stored under pressure, usually in steel cylinders. LPG is heavier than air, non-toxic and odorless. A smelling agent is added to aid users to detect leaks. LPG is a safe, economical and convenient fuel as it has high calorific value $(13.8 \mathrm{kWh} / \mathrm{kg}$, which is equivalent to 13.8 units of electricity), provides instantaneous heat, is easy to ignite and clean-burning and is very portable.LPG is stored and handled as a liquid when under pressure inside a LPGas container. When compressed moderately at normal temperature, it becomes liquid. When gas is withdrawn, the pressure drops and the liquid reverts to gas. This means that it can be transported and stored as liquid and burnt as gas. The expansion ratio of gas liquid is $270: 1$ at atmospheric pressure. It is expansion factor which makes LP-Gas more economical to transport and store large quantities of gaseous fuel in a small container. LPG appliances include: stoves/ovens, grills, heaters (portable and fixed), instantaneous water heaters, lamps (portable and fixed), refrigeration and welding plant, and Bunsen burners. Appliances are designed to operate both at an unregulated high pressure (e.g. CADAC (or similar) type of camping appliances) and at a lower pressure controlled by a regulator mounted on the gas storage cylinder. High pressure and low-pressure appliances are not interchangeable. Most households use gas appliances with a small dedicated gas cylinder, rather than a reticulated system of gas piping and fixed storage cylinders.

Many researchers have studied the analysis of LPG cylinder using composite materials using various commercial softwares available like Ansys [1-3] for the comparison of stress, strain and structure. It is shown that the stable angle of inclination of the fibers, where no strain-induced fiber rotations occur, deviates from the so-called 'ideal' fiber angle predicted by netting analysis by an amount that depends on the matrix-to-reinforcement-stiffness ratio [4]. But any pressure vessel made up of composite material like GFRP should be analyzed for various parameters related to the manufacturing procedure of the cylinder unlike conventional steel cylinder [5]. When the initial angle of inclination of the fibers deviates from the stable angle, the application of strain produces fiber rotation and nonlinear stress-strain relations result.

\subsection{Design Constraints}

The design of the LPG Cylinder is to be carried out considering the condition that the deformation or displacement and stress distribution are radial when only internal pressure is acting. Further, Radial displacement should be zero at junction point holding surface to handling case. The radial displacement is the component of a change in position in the radial direction as shown in Fig. 1.
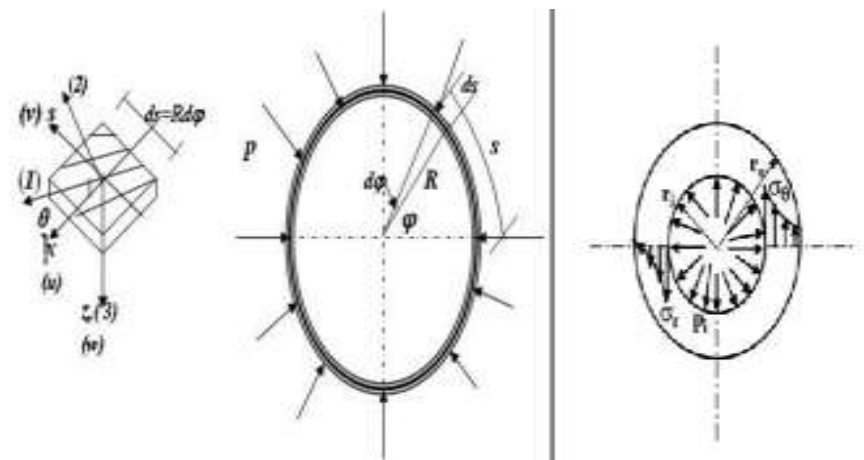

Fig. 1: Radial and stress distribution within the cylinder wall when only internal pressure is acting. 
Steel Cylinders are not manufactured in a single joint but are welded. While composite cylinders are manufactured in a single joint, Composite components cannot be welded like the steel cylinder. Composite Cylinders are winded using Filament Winding technique as shown in Fig. 2.

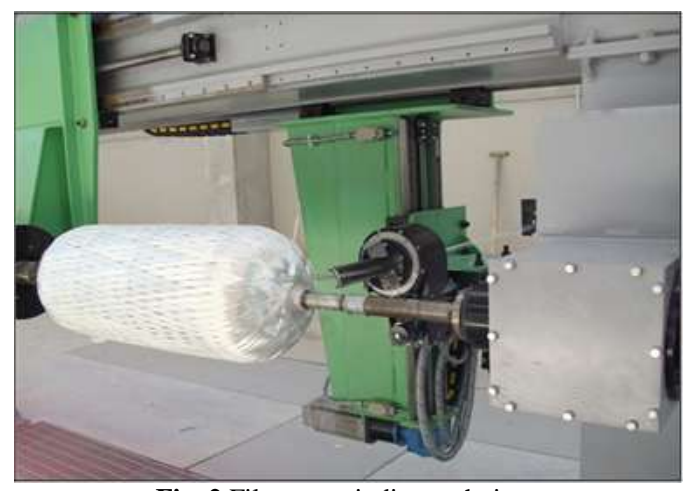

Fig. 2 Filament winding technique

Compared to Steel Cylinders, Composite Cylinders are costlier. Composite cylinders are safer than steel cylinder. Composite Cylinders due to a rubber lining inside, they are $100 \%$ leak proof. If mass production of composite cylinders are done then the cost may get reduced.

\subsection{Design Loads}

Operating Pressure, Working Pressure and Design Pressure are the major important design loads to be considered. In principle the maximum values that are allowed for operating pressure must be less than that of the working pressure and that of working pressure should be greater than that of the design pressure. Factor of safety (FOS) is another important load parameter and mathematically FOS is the ratio of Ultimate(Yield) Stress to the Design Stress. Considering the factor of safety for the Composite Cylinder as 2.5 , the operating pressure which is the product of Design Pressure and factor of safety can be calculated as $3.0 \mathrm{MPa}$ assuming the operating pressure as $1.2 \mathrm{MPa}$.

\section{Material Properties}

The detailed material data is given in table 1 .

Table1: Cured Composite - E-Glass Fiber (1200Tex)/Epoxy LY556

\begin{tabular}{|c|l|l|}
\hline S. No. & Parameters & Value \\
\hline 1. & Longitudinal modulus, E1 & $44 \mathrm{GPa}$ \\
\hline 2. & Transverse modulus, E2 & $10 \mathrm{GPa}$ \\
\hline 3. & Shear modulus, G12 & $8 \mathrm{GPa}$ \\
\hline 4. & Poison's ratio,v12 & 0.24 \\
\hline 5. & Longitudinal tensile strength, T1 & $800 \mathrm{MPa}$ \\
\hline 6. & Transverse tensile strength, T2 & $18 \mathrm{MPa}$ \\
\hline 7. & Longitudinal compressive strength, C1 & $400 \mathrm{MPa}$ \\
\hline 8. & Transverse compressive strength, C2 & $85 \mathrm{MPa}$ \\
\hline 9. & In-plane shear strength, S12 & $44 \mathrm{MPa}$ \\
\hline 10. & Density & $2100 \mathrm{~kg} / \mathrm{m}^{3}$ \\
\hline 11. & Fiber volume fraction, Vf & 0.6 \\
\hline
\end{tabular}

\section{Classical Lamination Theory (CLT)}

The material properties of the drive shaft were analyzed with Classical Lamination Theory (CLT). The variable of the laminate thickness has a big effect on the buckling strength and slight effect on bending natural frequency. From the properties of the composite materials, at given fiber angles, the reduced stiffness matrix can be constructed. The expressions of the reduced stiffness coefficients $Q_{i j}$ in terms of engineering constants are as follows:
Stiffness Matrix $[Q]=\left[\begin{array}{ccc}Q_{11} & Q_{12} & 0 \\ Q_{12} & Q_{22} & 0 \\ 0 & 0 & Q_{66}\end{array}\right]$

$\frac{E_{1}}{v_{12}}=\frac{E_{2}}{v_{21}}$

Where,

$Q_{11}=\frac{E_{1}}{1-v_{12} v_{21}}$

$Q_{12}=\frac{v_{12} E_{1}}{1-v_{12} v_{21}}$

$Q_{22}=\frac{E_{2}}{1-v_{12} v_{21}}$

$Q_{66}=G_{12}$

Reduced Stiffness matrix $[\bar{Q}]=\left[\begin{array}{lll}Q_{x x} & Q_{x y} & Q_{x s} \\ Q_{y x} & Q_{y y} & Q_{y s} \\ Q_{s x} & Q_{s y} & Q_{s s}\end{array}\right]$

The extensional stiffness matrix [A] is the summation of the products of the transformed reduced stiffness matrix $[Q]$ of each layer and the thickness of this layer as:

$$
[A]=\sum_{i=1}^{n}[\bar{Q}]_{\theta}\left[Z_{k}-Z_{k-1}\right]
$$

The A matrix is evaluated and the thickness of each ply is calculated in reference to their coordinate location in the laminate. First the normal forces $\mathrm{N}_{\mathrm{x}}, \mathrm{N}_{\mathrm{y}}, \mathrm{N}_{\mathrm{xy}}$ are calculated and with the help of [A] matrix, strains are evaluated.

$[N]=[A][\varepsilon]+[B \rrbracket K]$

$[B]$ is Body Force Vector and $[K]$ is Curvature Matrix and in this case $[B]=0$, therefore $[N]=[A][\varepsilon]$ and hence Strain matrix is given by

$[\varepsilon]=[A]^{-1}[N]$

In composites the stresses will vary from layer to layer according to the fiber orientation. Here we are calculating stresses for both hoop and helical layer.

$$
[\sigma]=[Q]_{\theta}[\varepsilon]
$$

\section{Metallic boss Calculation $\&$ angle variation at dome}

We assume thickness of the cylinder to be $1 \mathrm{~mm}$ at radius $150 \mathrm{~mm}$. For different values of $\mathrm{R}$ and $\alpha$, the thickness values are calculated. We calculate the angle by substituting different values of $\mathrm{R}$ till we get an angle of $\boldsymbol{\alpha}=\mathbf{5 4 . 1 7 ^ { \circ }}$. At that angle, the value of $R$ is noted 
down and is substituted in the above formulae and thickness is calculated. At that particular $\mathrm{R}$ where $\boldsymbol{\alpha}=\mathbf{5 4 . 1 7}^{\mathbf{0}}$ we calculated the Tip Radius. It is found to be at $\mathrm{R}=37$ and therefore Tip radius is given by

$$
\text { Tip Radius }=\mathrm{R} * 1.1=40.7 \mathrm{~mm}
$$

\section{Results and Conclusions}

Considering $\mathrm{E}_{1}=44 \mathrm{GPa}, \mathrm{E}_{2}=10 \mathrm{GPa}, \mathrm{G}_{12}=8 \mathrm{GPa}, v_{12}$ (Poisons ratio) $=0.24$, we can calculate $v_{21}$ from equation 10 and is given by $v_{21}=0.05$. Further using the equations from 11 to 16 the stress is evaluated as follows

$$
\left[\sigma_{90}\right]=\left[\begin{array}{c}
204.89 \\
294.89 \\
0
\end{array}\right] \mathrm{MPa}
$$$$
\left[\sigma_{11.5}\right]=\left[\begin{array}{c}
776.8 \\
118.63 \\
87.39
\end{array}\right] \mathrm{MPa}
$$$$
\left[\sigma_{-11.5}\right]=\left[\begin{array}{c}
776.8 \\
118.63 \\
-87.39
\end{array}\right] \mathrm{MPa}
$$

The stresses at different value of angles in the respective directions are calculated and stresses are within limits. The analysis of LPG cylinder using GFRP composite material and its comparison with that of steel metallic material is carried out using classical lamination theory. The following conclusions have been drawn

1. The composite LPG cylinder designed is meeting the stipulated MEOP.

2. The new method proposed for analysis of filament wound composite cylinder is worked out to be efficient in accurately predicting the structural response.

3. The design stresses are within safe limits.

\section{References}

[1] Ashok. T, Hari Krishna. A, "Analysis of LPG Cylinder Using Composite Materials", IOSR-JMCE, 9-2(2013), 33-42.

[2] Yashraj Jayant salunke, Mangrulkar. K. S, "Stress Analysis of a Composite Cylinder for the Storage of Liquefied Gases", IJETT, 13-8(2014), 394-395.

[3] Moyahabo Bradley Moketla, Mukul Shukla, "Design and finite element analysis of FRP LPG cylinder", IJICA, 1-3(2012), 121-124.

[4] Evans. J. T, Gibson. A. G, "Composite angle ply laminates and netting analysis", 458-2028(2002), DOI: 10.1098/rspa.2002.1066.

[5] Reza Mohammadzadeh, Gheshlaghi1 Mohammad, Hassan Hojjati, "Analysis of Composite Pressure Vessels", Fracture of Nano and Engineering Materials and Structures, Proceedings of the 16th European Conference of Fracture, Alexandroupolis, Greece, (2006), 335-336.

[6] Rosato. D. V, Grove. S, "Filament Winding: Its Development, Manufacture, Applications and Design", Interscience Publishers, A division of John Wiley \& Sons, Inc., New York.

[7] Peters. S. T, Humphrey. W. D, Foral. R. F, "Filament Winding Composite Structure Fabrication", Second Edition, Society for the Advancement of Material and Process Engineering (SAMPE).

[8] Vogt. C. W et. al, "Development of Filament Wound Case Design for Solid Propellant Rocket Motors in the 260-inch Diameter Class", National Aeronautics and Space Administration, 1969.

[9] Ramesh Chandra, Viswanathan. K. S, Jayasurya. M, "Mechanical Properties of Carbon-Epoxy Composites", Proceedings of the Seminar Workshop on Carbon Fibres and their Applications, 1986

[10] Nagesh, "Finite-element analysis of composite pressure vessels with progressive degradation", Defence science journal, DESIDOC 53-1(2003), 75-86
[11] Jean- Marc.gautier, "Strategic missile solid rocket motor cases qualification", AIAA 2006-4597.

[12] Cho-Chung liang, Hung Wen Chen, "Optimum design of fiberreinforced composite cylinder skirts for solid rocket cases subjected to buckling and overstressing constrains", Composites: Part B 34 (2003) 273-284.

[13] Stein Tenden, "Composite Cased Solid Propulsion Rocket Motor for Hyper Velocity Missile Demonstration Program", AIAA-20075791.

[14] Betti. F et. al, "Design and Development of VEGA Solid Rocket Motors composite cases", AIAA 2007-5810.

[15] Remya Gopi, Beena B. R, "Finite Element Analysis of GFRP LPG Cylinder", IJEDR, 3-4(2015), 642-649.

[16] Dhanunjayaraju. M, Rakesh Babu. T. L, "Stress Analysis of LPG Cylinder with Composites", IJAR, 1-12(2015), 1042-1045.

[17] Alok Tom et al, "Design and Analysis of LPG Cylinder", IJEAS, 62(2014), 17-31

[18] Abishek, Rishi. J. P, "Stress Analysis of a Composite Material Cylinder for Storage of Liquified Petroleum Gas (LPG)", NCAMES(2016), 244-247. 